The essays draw inspiration from experience from the mid-1960s up to the present. This is one of the strengths of the ideas promoted in the essays. They are not presented as a 'new' invention but rather as a re-articulation and re-interpretation of citizen-led solutions to the challenges and complexities of current times. Thus, the temptation of promoting yet another fashion in development is curtailed to a great extent. This widens the potential usage of ideas on re-invigorating democracy and citizenship through civic agency by a wide spectrum of actors from aided-development and beyond.

\title{
Udan Fernando
}

Senior Consultant, Context International Cooperation, Cornelis Houtmanstraat 15, 3572 LT Utrecht, The Netherlands.

E-mail: uf@developmenttraining.org

\section{Duncan Green, From Poverty to Power: How Active Citizens and Effective States can Change the World. Oxford: Oxfam, 2008. xvi + 522 pp. $£ 15.95$ paperback.}

This book provides a very exhaustive account of the major debates in international development, touching on topics as diverse as education, health, climate change, migration and markets. The main argument running through the book is that 'development, and in particular efforts to tackle inequality, is best achieved through a combination of active citizens and effective states' (p. 12). This explains the title of the book: it argues for a shift away from believing that poverty can be reduced by economic growth towards recognizing the central role of politics in development, in other words, how citizens and states interact to produce or reduce inequality, vulnerability and unequal power relationships. The numerous real-life examples and case studies serve to illustrate this argument.

By 'active citizenship', the author refers to the combination of rights and obligations that link individuals to the state. Active citizens use their political, civil, and social rights to improve the quality of political or civic life. As for 'effective states', the author denotes 'states that can guarantee security and the rule of law, and can design and implement an effective strategy to ensure inclusive economic growth' (p. 12).

While the book's core argument is not new (at least in academia and increasingly with donors), its unique contribution lies in its holistic treatment of it and the synthesis of a huge amount of (quantitative and qualitative) data in one place, including a bibliography of almost thirty pages.

Following the introduction, the second part of the book entitled 'Power and Politics' sets out the main components that shape 'active citizens' and 'effective states': (human) rights, religious beliefs, education, technology, civil society, property rights, elections and democratic governance, corruption and rents, among others.

However, the remaining parts on 'Poverty and Wealth' (which is in need of a postscript on the current economic crisis), 'Risk and Vulnerability' and 'The International System' read rather as appendices - while they contain good summaries about the current states of knowledge and debate on various topics, they do not add much to the arguments put forward. Rather, they often simplistically repeat the mantra of effective states and active citizenship as the panacea to all ills. Furthermore, while the introduction mentions eight case studies, these are not clearly presented at the outset or linked to each other throughout the text. 
For an academic, the main shortcoming of the book is its superficial treatment of some key concepts: 'effective states' are equated with 'developmental states' and there is little discussion of how 'enlightened leadership' (p. 11) that was so crucial to the push for redistribution (and plays an important role in many of the success stories told in this book) could be brought about today. The account also generally paints a very benevolent picture of such leadership and hardly mentions the harsher, repressive side of 'developmental states'. Indeed, the crucial question of whether effective states are compatible with active citizens is only addressed in one textbox on little more than a page (p. 94). Another concept that is not defined properly (only in the Annex, and missing in the Glossary) but frequently referred to is that of 'institutions'. Similarly, 'accountability' is only mentioned in the context of development aid. Most regrettable is the fact that the innovative methodological framework for analysing the case studies ('How Change Happens') is relegated to the Annex rather than presented up-front as the guiding analytical tool, although the author does acknowledge that this is a work in progress.

For development practitioners, the case studies and policy recommendations are probably too brief to serve as more than inspiration rather than as a solid basis for policy formulation and programming. For example, the case of women's NGOs campaigning for the reform of the Family Law in Morocco presents the change in the law as an end in itself and is silent on the shortcomings in implementation. There is also an awkward tension inherent in success stories that are partly based on violence and what Oxfam is comfortable with in terms of its advocacy.

Given the wealth of information contained in this book, the reader would have appreciated succinct conclusions - however, they are generally very short (the conclusion of the entire book is only two pages long) and sometimes emphasize points that do not reflect the bulk of the text (as in a discussion of cosmopolitan elites in Part Two). Some editing would also have helped to avoid repetitions (the sections on humanitarian relief, war, refugees, and climate change in Part Five could easily have been merged with material in Part Four).

This book clearly does not have the ambition to be a major scholarly work, but is mainly addressed to policy makers, campaigners and activists in NGOs and elsewhere. Given its wealth of case studies and examples, it may also be suitable for a general undergraduate course in development studies, especially if complemented by a more rigorous conceptual framework. In short, this book is a valuable addition to debates on issues in development, though occasionally its broad scope comes at the expense of more nuanced and in-depth understanding and analysis.

\section{Sylvia I. Bergh}

Institute of Social Studies, Kortenaerkade 12, 2518 AX The Hague, The Netherlands. E-mail: bergh@iss.nl

\section{Edwin C. Baker, Media Concentration and Democracy: Why Ownership Matters. Cambridge: Cambridge University Press, 2007. xiii + 256 pp. $£ 14.99 / \$ 22.99$ hardback, $£ 35.00 / \$ 65.00$ paperback.}

Media ownership concentration has been a recurrent theme in the debate on media and communication. The debate arguably was ignited by the publication of Ben Bagdikian's Media Monopoly in 1983. However, a number of eminent scholars continue to enrich the debate, making it intellectually more probing and exciting than 